\title{
Exploration on molecular dynamics simulation methods of microscopic wetting process for coal dust
}

\author{
Qi Zhang ${ }^{1,2} \cdot$ Xinyi Chen ${ }^{1,2} \cdot$ Hetang Wang ${ }^{1,2}$ (i) $\cdot$ Chaohang $\mathrm{Xu}^{3}$
}

Received: 24 September 2020/Revised: 23 January 2021 / Accepted: 5 February 2021 / Published online: 11 March 2021

(C) The Author(s) 2021

\begin{abstract}
Wet dust removal is one of the main technical measures in coal dust control, and coal dust wetting is the key factor to determine the effect of wet dust removal. In order to explore the micro-wetting process of coal dust, this paper uses molecular dynamics simulation to study the micro-wetting process of coal dust in different simulation conditions. The molecular dynamics simulation was carried out under different ensemble, thermodynamic states as well as relaxation pretreatment methods, then the $\mathrm{H}_{2} \mathrm{O}$ molecular layer and coal dust molecular layer in each simulation were quantitatively analyzed by relative concentration. The research results show that a method for establishing molecular model of lignite is proposed and the 2D periodic surface structure is more reasonable. The surface system of coal- $\mathrm{H}_{2} \mathrm{O}$ molecule is established by NVT aeration method, where the simulation result is close to the actual coal dust wetting process. The simulation effect of medium and large coal dust $-\mathrm{H}_{2} \mathrm{O}$ molecular system is better than that of small coal dust $-\mathrm{H}_{2} \mathrm{O}$ molecular system. This study provides a new solution for changing the empirical method of molecular dynamics simulation of coal system wetting and oversimplification of coal system.
\end{abstract}

Keywords Coal dust $\cdot$ Wettability $\cdot$ Molecular dynamics $\cdot$ 2D periodic surfaces $\cdot$ NVT ensemble

\section{Introduction}

A large amount of dust is produced in the process of coal mining and transportation, which seriously affects the safe production of enterprises and the health of employees. In recent years, the problem of dust management has been paid more and more attention. (Luo et al. 2017; Reed et al. 2018, 2019; Shahan and Reed 2019; Yao et al. 2020; Tan

Hetang Wang

wanghetang@cumt.edu.cn

1 Key Laboratory of Gas and Fire Control for Coal Mines, Ministry of Education, China University of Mining and Technology, Xuzhou 221116, China

2 National Professional Center Laboratory of Basic Research of Mine Gas and Dust Control Technology, China University of Mining and Technology, Xuzhou 221116, China

3 School of Safety Science and Emergency Management, Wuhan University of Technology, Wuhan 430070, China et al. 2020). Dust reduction by wetting as the most commonly used method is far more effective than ventilation. Coal seam water injection is a fundamental and efficient method to prevent and control dust from its source (Cheng et al. 2012). In terms of mining and tunneling, a variety of hydrating dust collectors have been popularized (Wang et al. 2017, 2014).

The wettability of coal is closely related to its metamorphic degree, chemical structure, industrial components, bedding structure, pore characteristics and liquid properties (Meng et al. 2019; Wang et al. 2019; Xu et al. 2017). A lot of research results for the wettability of coal dust are characterized by the contact angle-a macroscopic property, leaving the microscopic property somewhat undiscovered. Thus, experimental results always can be inaccurate.

Molecular dynamics (MD) is a simulation method that enables atoms or molecules to interact with each other in a system with given conditions (time, temperature, pressure 
and other macro thermal conditions). The dynamic evolution process can be presented and various properties of the system can be calculated by MD. MD can reveal the law of material evolution from the micro system of atomic level, which can be used as a micro explanation (Sharma 2019) and it is also a tool to verify theories. The reliability of modern molecular dynamics simulation methods, combined with the First-Principle (or ab initio calculations) and other quantum methods can be considered noteworthy (Glukhova 2017).

Yet, molecular dynamics simulation, an effective research method on micro systems, has some difficulties in the practice of coal systems with complex chemical structure and an irregular arrangement. At present, it is a common practice to choose simulation researches of other materials and apply their parameters to coal related systems, so there is no recognized optimal set of simulation methods and parameters for coal. In the past, $\mathrm{H}_{2} \mathrm{O}$ molecular model with a fixed boundary and a droplet shape with molecules of magnitude of only a few thousand have been established to study the simulation and contact angle calculations for solid materials. Qiang et al. and Zhang et al. $(2018,2020)$ doubt the practical significance and rationality of this approach of the $\mathrm{H}_{2} \mathrm{O}$ system's macroscopic shape at such a small micro scale. Still, this approach is a common practice in MD simulations to investigate the wettability of solid materials. As a consequence, there is barely research using the microscopic molecular distribution of $\mathrm{H}_{2} \mathrm{O}$ on the surface of coal dust to directly reflect the wettability of coal dust, which is considered more reasonable.

In this paper, through the molecular dynamics simulation of coal dust systems, at different scales wetted under different simulation conditions and modeling methods, the distribution of micro scale wettability on the coal surface is revealed. Furthermore, the difference and reliability of results under various simulation conditions are revealed. Ultimately, more reliable simulation and modeling methods, procedures and parameters are obtained, which is a preliminary attempt to change the status quo of over simplifying the coal system and empiricism of the molecular dynamics simulation methods of other materials.

\section{Molecular dynamics simulation}

\subsection{Modeling and optimization}

In this paper, the Australia's Yalluourn coal structure studied by Kumagai is selected as the basic model of coal (Xia 2017). Firstly, a single coal and $\mathrm{H}_{2} \mathrm{O}$ molecular model were sketched in Materials Studio. The structure of coal is shown in Fig. 1.

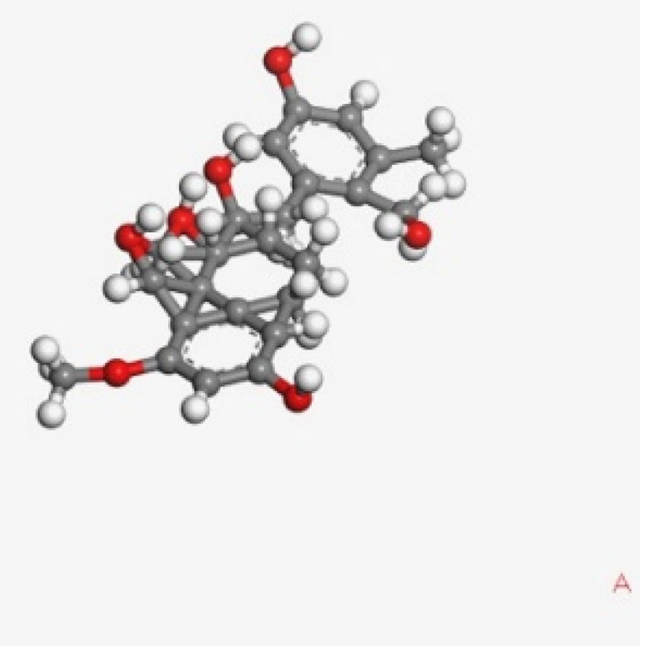

Fig. 1 Structure of Yalluourn brown coal molecule

In order to improve the accuracy and efficiency of the simulation, geometric optimization, namely energy minimization, is needed for the established coal and $\mathrm{H}_{2} \mathrm{O}$ molecular models. For the initially established molecular model with an imperfect initial structure, the CASTEP module was used to run a geometry optimization task to minimize energy (Imai et al. 2001). The molecular configuration after the geometric optimization is shown in Fig. 2 and these changes include the atomic position, bond length and bonding patterns of the coal molecular.

After the optimization of a single coal and $\mathrm{H}_{2} \mathrm{O}$ molecule, the molecular layers were established by Amorphous Cell module. The coal molecular number was temporarily set as 10 and the target density as $0.7 \mathrm{~g} / \mathrm{cm}^{3}$ which is an approximate general density of lignite. The geometric optimization was carried out by DMol3 to obtain an ideal initial coal molecular layer structure (Xu et al. 2007). The layer of coal after establishment is shown in Fig. 3a. The energy minimized layer is shown in Fig. 3b. Compared with the same position of the coal molecular layer in Fig. 3a, the optimized layer in Fig. 3b is more compact, which means that the optimization result is well.

Then, since the research object is solid-liquid, the position and velocity of coal as a solid should not change with the simulation. This process can be completed by setting Constrain command for coal molecule. The validity of this approach will be verified in Sect. 3.2. At the same time, the Amorphous Cell module is adopted to establish a $\mathrm{H}_{2} \mathrm{O}$ molecule layer with a number of 100 , as shown in Fig. 4a. Also, $\mathrm{H}_{2} \mathrm{O}$ is liquid phase, whose target density is set as $1.0 \mathrm{~g} / \mathrm{cm}^{3}$. Geometric optimization was carried out to 

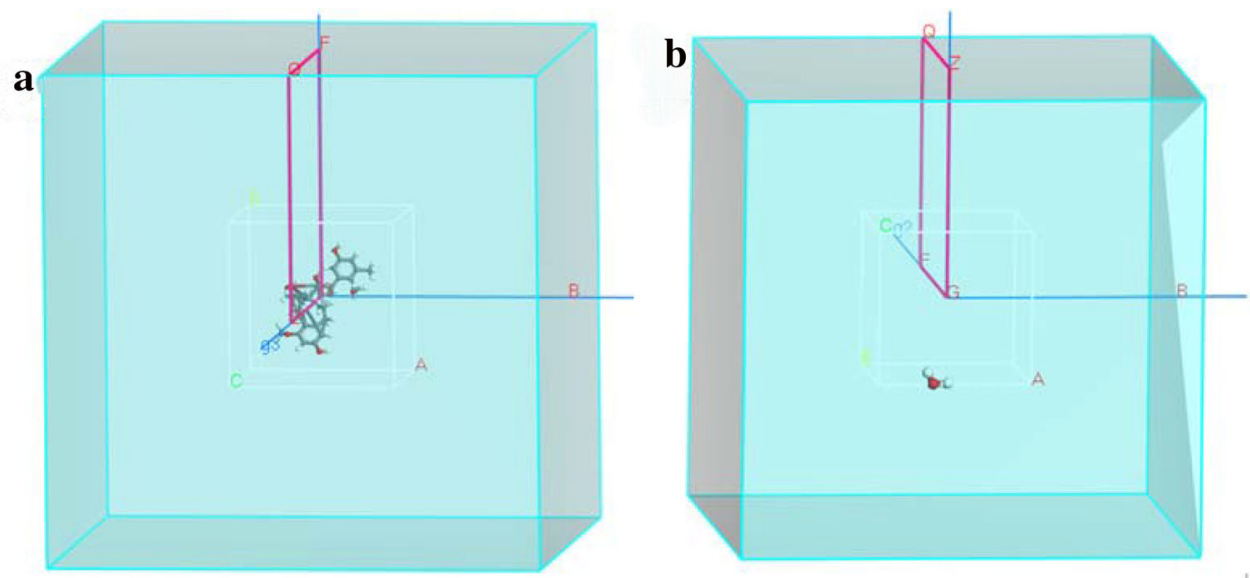

Fig. 2 Molecular structure after CASTEP geometric optimization respectively a Lignite; $\mathbf{b} \mathrm{H}_{2} \mathrm{O}$
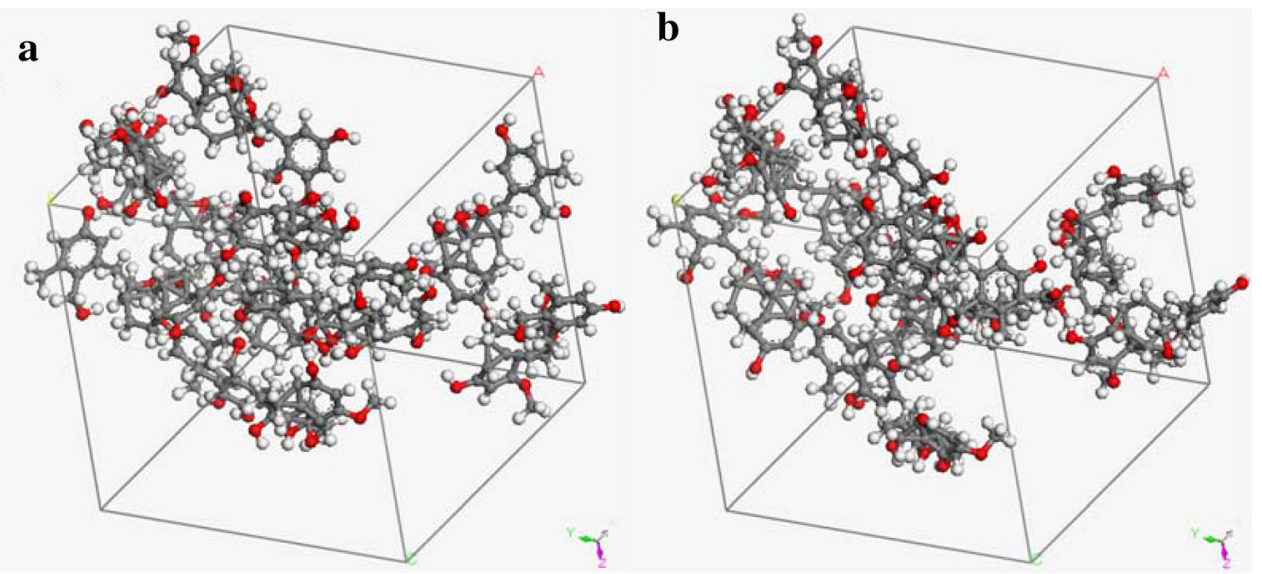

Fig. 3 Building and optimizing lignite system(small) a Lignite system(small) built by Amorphous Cell; b Lignite system(small) after DMol3 geometric optimization
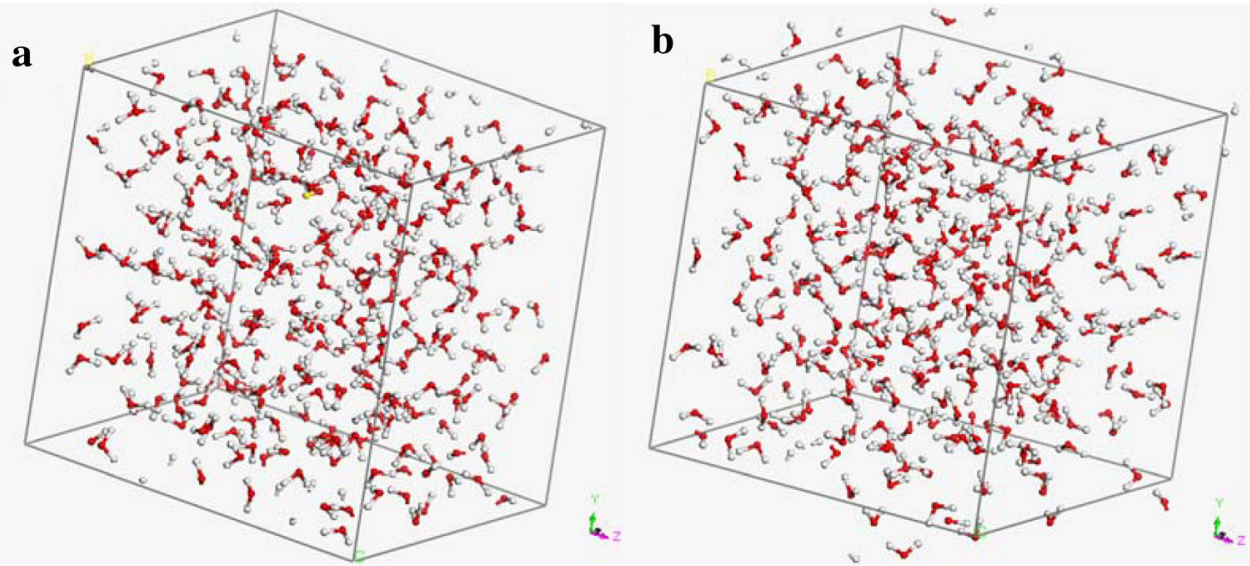

Fig. 4 Building and optimizing $\mathrm{H}_{2} \mathrm{O}$ system(small) a $\mathrm{H}_{2} \mathrm{O}$ molecular system (small) built by Amorphous Cell; b $\mathrm{H}_{2} \mathrm{O}$ molecular system (small) after CASTEP geometric optimization

get the ideal initial $\mathrm{H}_{2} \mathrm{O}$ molecular layer structure. Subsequently, the energy of the molecular layer is minimized by the CASTEP module too, which is shown in Fig. 4b. It can be seen that the optimized molecular layer becomes sparser and has lower energy by analyzing this figures. 
Establishing molecular layer respectively and their preliminary structure optimization, this paper adopted Build Layers command for combining the two systems into one. Both options of layer building were attempted, that is, 2D periodic surface structure and 3D periodic crystal structure as provided by Build Layers, shown in Fig. 5a and $\mathrm{b}$. For the $2 \mathrm{D}$ periodic surface structures, the areas were $452.098 \AA^{2}, 750.690 \AA^{2}$ and $955.567 \AA^{2}$ for small, medium and large-scale Coal- $\mathrm{H}_{2} \mathrm{O}$ Molecular Systems respectively; and for $3 \mathrm{D}$ periodic crystal structures, the volume of the simulation box was $14,378.358 \AA^{3}$. The results of the two modeling methods are discussed in Sect. 3.1. The established layers and surface structures were also minimized with DMol3, as shown in Fig. 5c. It shows that partially discrete coal molecular converge and $\mathrm{H}_{2} \mathrm{O}$ molecular become uniform and loose distribution after optimization. For coal, it is a solid substance whose density is higher, so the coal molecular tends to shrink and becomes denser. In addition, $\mathrm{H}_{2} \mathrm{O}$ is a fluid and low-density substance, so it becomes loose. Therefore, the optimization result is reasonable.

\subsection{Force field and ensemble selection}

The MD simulation of the Coal dust- $\mathrm{H}_{2} \mathrm{O}$ molecular system studied in this paper was based on the Forcite module in Materials Studio. In this paper, the ab initio force field compass was used to calculate the forces of other substances with the same element for replacing the experiment-based potential energy function (Savin and Mazo 2020). All the calculations were carried out under the COMPASS force field, which is suitable for organic or some inorganic molecules or generally used to calculate the properties of materials (Liu et al. 2020). The Coal dust$\mathrm{H}_{2} \mathrm{O}$ molecular system studied in this paper was an open system with a constant temperature $285 \mathrm{~K}$ and the number of particles was assumed to be constant. The canonical ensemble NVT was therefore selected for the molecular dynamics simulation in this paper.

\subsection{Parameters setting}

For the surface structure, in the dynamics settings of Forcite, the initial velocity was set to random allocation. The Anderson method was used to provide a constant temperature. Main parameters are shown in Table 1. In addition to, the charge was automatically distributed; for the charge addition method, the Ewald method was selected to calculate the Coulomb interaction (Abdulnour Y. Toukmaji 1996); whilst the atom-based method was selected to calculate the van der Waals interaction.

\subsection{Pretreatment of simulation}

Prior to running the molecular dynamics simulation, anneal was applied to fully relax the system (Yan and Luo 2014). Specifically, five annealing cycles were run under the NVT ensemble, with the initial temperature of $298 \mathrm{~K}$, heated to $500 \mathrm{~K}$ and then cooled to $298 \mathrm{~K}$. The number of steps was 5000; the time step was $1 \mathrm{fs}$; and the simulation time was 5 ps. Through annealing, the total energy of the system was even smaller and reached a more stable state-this was a more appropriate structure for any molecular dynamics to start with. The output configuration is shown in Fig. 6 .
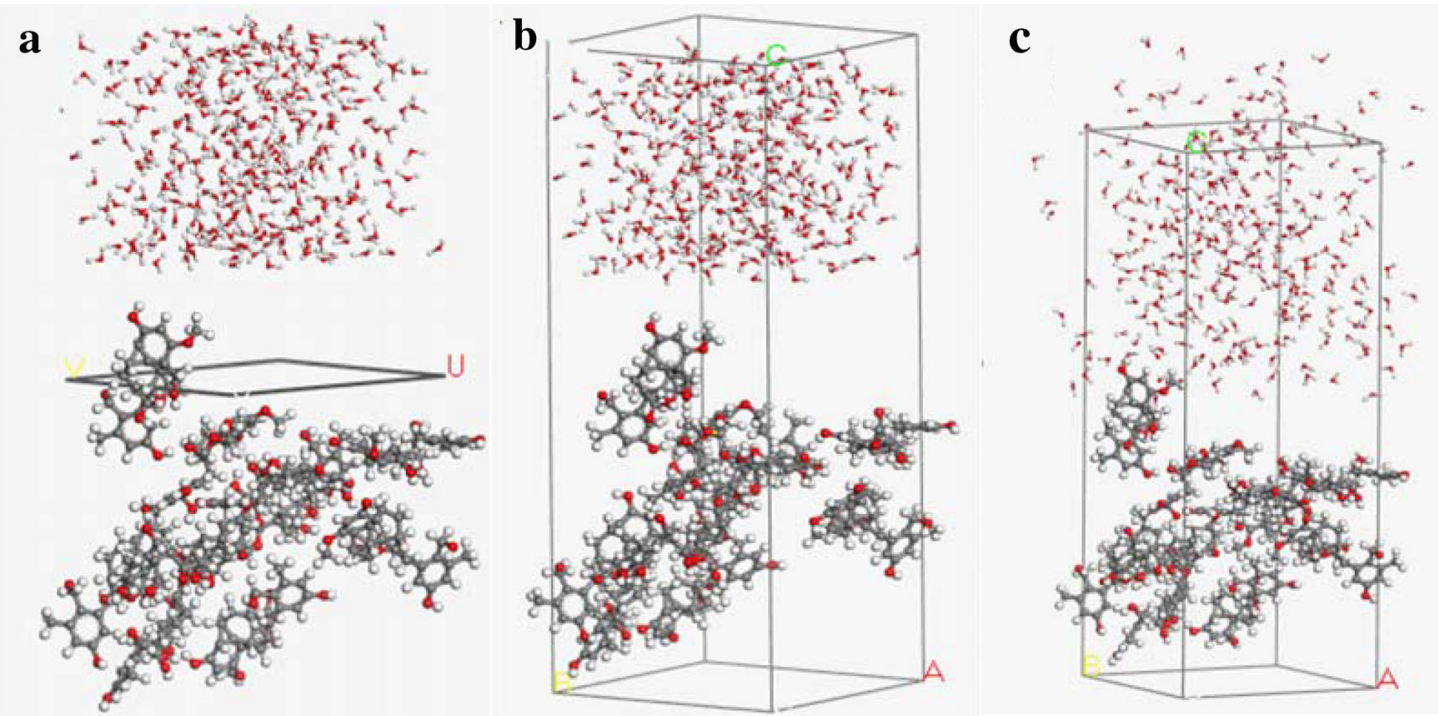

Fig. 5 The Coal- $\mathrm{H}_{2} \mathrm{O}$ Molecular System(small) built by Build Layers and optimization a 2D periodic surface system; b 3D periodic lattice system; c The optimized 3D periodic lattice system 
Table 1 Setting operating parameters

\begin{tabular}{ll}
\hline Parameter & Setting \\
\hline Time step & $1.0 \mathrm{fs}$ \\
Simulation steps & 100,000 \\
Total simulation time & $100 \mathrm{ps}$ \\
Current structure file & Output once every 500 units \\
Quality & Medium \\
Charge & Automatically distribute \\
The charge addition method & Ewald method \\
& Atom-based method \\
\hline
\end{tabular}

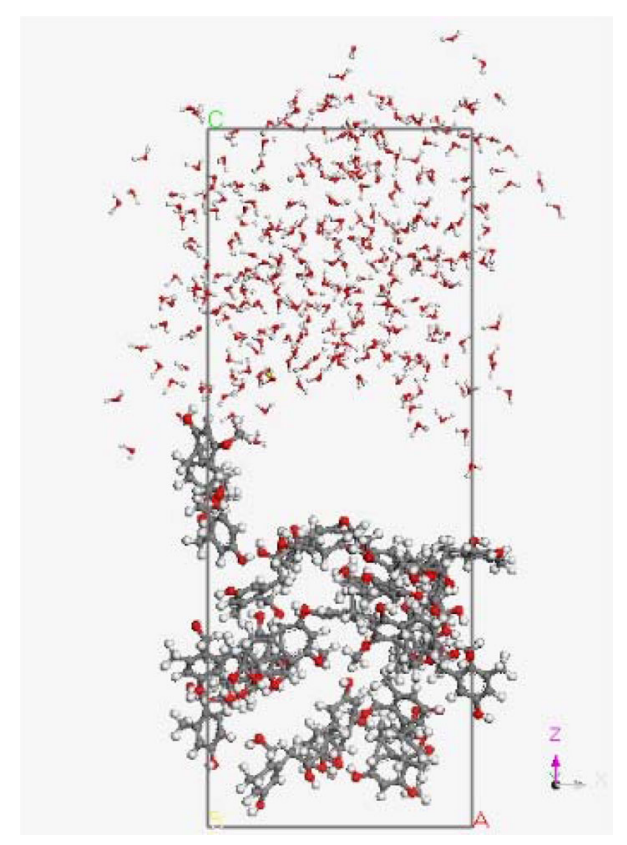

Fig. 6 Coal- $\mathrm{H}_{2} \mathrm{O}$ Molecular System after geometric optimization and anneal (small; crystal)

After the step of annealing, compression-decompression treatments were carried out on crystal Coal dust- $\mathrm{H}_{2} \mathrm{O}$ Molecular System in NPT by Forcite dynamics, with the pressure set as 1, 0.8, 0.6, 0.4, 0.2 and $0.1 \mathrm{MPa}$ respectively by the same simulation parameters as annealing. The influence of this treatment as a variable on crystal system simulation will be discussed in Sect. 3.1. The output configurations of each compression-decompression are shown in Fig. 7 (the above treatment cannot be carried out on the surface systems). Not only can this treatment gradually reach the pressure value of approximately real atmospheric pressure, but it also helped the system reach an even more stable state on the basis of annealing, which made the dynamic simulation results more reliable. After annealing and compression-decompression treatments, the molecular dynamics simulation of the relatively stable crystal Coal dust- $\mathrm{H}_{2} \mathrm{O}$ Molecular System was carried out with the same basic dynamics parameters as mentioned above.

\section{Results and discussion}

\subsection{Small-scale coal dust- $\mathrm{H}_{2} \mathrm{O}$ molecular system under various conditions}

The configurations are shown in Fig. 8a-d. At the same time, the files generated by Frame can be used to view the displacement of the $\mathrm{H}_{2} \mathrm{O}$ molecule system throughout the simulation process. It can be seen from the relative concentration analysis graph (Fig. 8e) that in the selected direction $(0,1,0)$, and $\mathrm{H}_{2} \mathrm{O}$ molecules were distributed in the range of $17 \AA$ to $48 \AA$ from the bottom to the top, while the lignite molecules' distribution ranged from 4 to $36 \AA$. The spatial distribution of the coal was irregular, which was determined by the model construction and geometric optimization. Its molecules were set in fixed positions and did not move with the dynamics, so there was no further analysis. The molecular layer of lignite and $\mathrm{H}_{2} \mathrm{O}$ molecules began to coincide at approximately the $36 \AA$ plane which was the initial position of lignite on its $+\mathrm{Z}$ side and continued to $17 \AA$ in the interior of lignite system, accounting for $59.375 \%$ of the $Z$ axis length of the coal dust in this system.

In the same system, the temperature rises to $295 \mathrm{~K}$ and other conditions remain unchanged. The $\mathrm{H}_{2} \mathrm{O}$ and lignite molecules were respectively distributed in the range of $17 \AA$ to $50 \AA$ and $2.8 \AA$ to $35.3 \AA$ and the $\mathrm{H}_{2} \mathrm{O}$ molecules were concentrated in the range of $25 \AA$ to $44 \AA$. The molecular layer of lignite and $\mathrm{H}_{2} \mathrm{O}$ molecules began to coincide at $35.3 \AA$ plane and continued to $16.8 \AA$ in the lignite system. According to Fig. 9, little difference was shown for the internal permeability and surface distribution on lignite molecules compared with $285 \mathrm{~K}$, so the simulation of other different temperatures was discontinued.

Although in the initial selection of a reasonable simulation ensemble, NVE was excluded considering the practical environment, its irrationality has not been proven yet. Therefore, the author has carried out the NVE dynamics simulation again under the same other conditions. Figure 10 shows that the diffusion and infiltration of $\mathrm{H}_{2} \mathrm{O}$ molecules in this ensemble are stronger than those under the NVT ensemble with a trend of diffusion around the coal dust and the accumulation on the contact surface between the coal and $\mathrm{H}_{2} \mathrm{O}$ molecular layers is significantly less than that of the NVT simulation.

With other conditions remaining constant, the simulation output configuration of the three-dimensional periodic cell system without pressurization is shown in Fig. 11a and the $\mathrm{H}_{2} \mathrm{O}$ molecules are disordered and highly diffused. The 


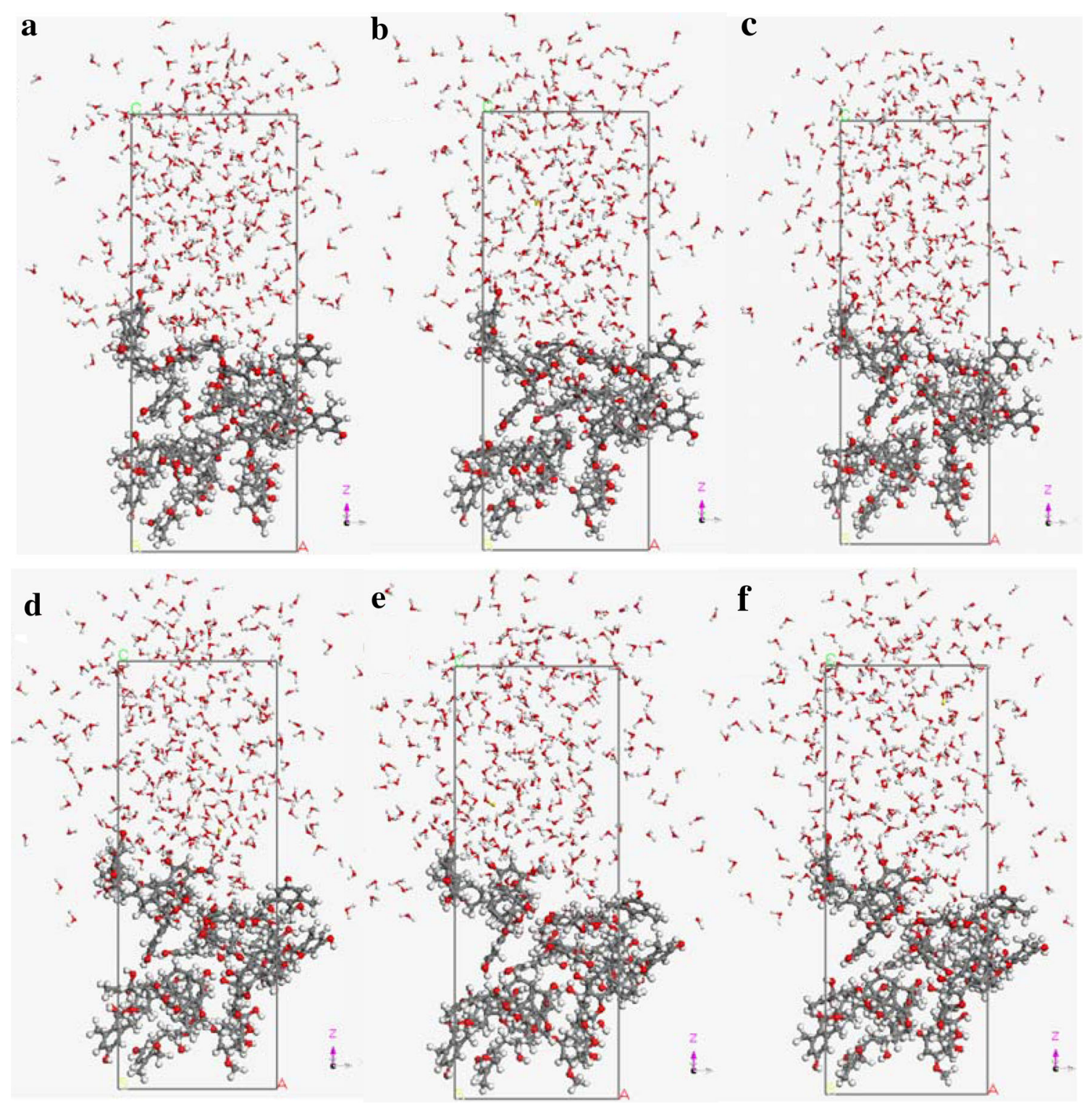

Fig. 7 Compression-decompression treatment on 3D periodic lattice system(small). a $1 \mathrm{MPa}$; b $0.8 \mathrm{MPa}$; $0.6 \mathrm{MPa}$; d $0.4 \mathrm{MPa}$; e $0.2 \mathrm{MPa}$; f $0.1 \mathrm{MPa}$

simulation output configuration after annealing and NPT pressurization of the same model and its relative concentration analysis are shown in Fig.11b, c. From Fig.11a, b, it is evident that the $\mathrm{H}_{2} \mathrm{O}$ molecules are more constrained as compared to those without annealing pressurization. According to Fig. 10c, the $\mathrm{H}_{2} \mathrm{O}$ and lignite molecules were distributed in the range of $20 \AA$ to $65.5 \AA$ and $3.5 \AA$ to $30.5 \AA$. The $\mathrm{H}_{2} \mathrm{O}$ molecules were relatively concentrated in the range of $28 \AA$ to $55 \AA$. The two layers began to coincide at the plane of about $30.5 \AA$ and continued to $20 \AA$ in the interior of the lignite system, accounting for about $38.89 \%$ of the $Z$ axis length of coal dust in this system. From $30.5 \AA$ to $55 \AA$ on the surface of lignite molecular system, the number of $\mathrm{H}_{2} \mathrm{O}$ molecules reached its peak part, accounting for $90.741 \%$ of the $Z$ axis length of the coal dust system. The distribution of $\mathrm{H}_{2} \mathrm{O}$ molecules in the area above $55 \AA$ gradually decreased to zero. It was apparent that the infiltration of $\mathrm{H}_{2} \mathrm{O}$ molecules into the interior of lignite was weaker than that of the surface system and the $Z$ axis distribution range of lignite surface increased, however, there is no accumulation sign with droplet flow. Consequently, 3D periodic cell systems are not appropriate for simulating coal dust wetting of the Coal dust- $\mathrm{H}_{2} \mathrm{O}$ Molecular Systems in this paper, though NPT pretreatment can indeed be an optimization approach to some extent.

This paper considers that the possible reason for this difference is that the three-dimensional cell system adopts 

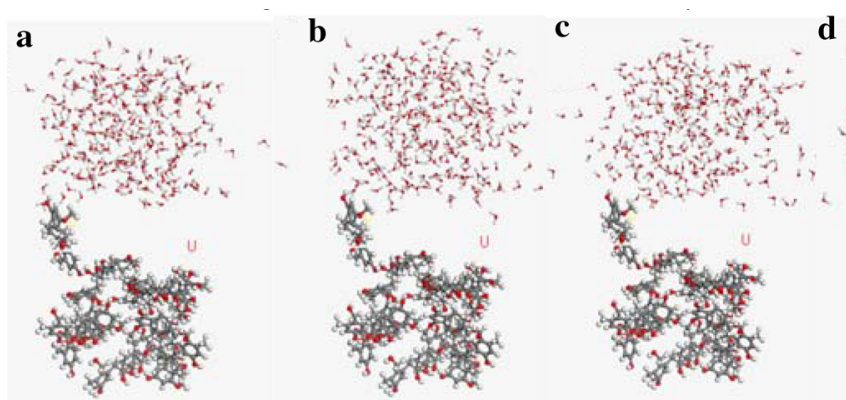

\section{d}

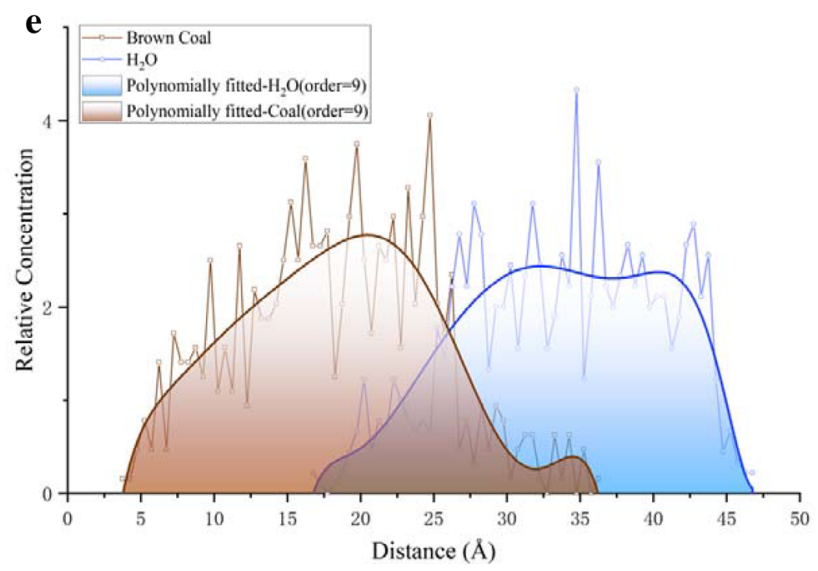

Fig. 8 Forcite MD simulation results of small-scale 2D periodic surface Coal- $\mathrm{H}_{2} \mathrm{O}$ Molecular System at $285 \mathrm{~K}$ and NVT. a Step 25,000; b Step 50,000; c Step 75,000; d Step 100,000; e Relative concentration by Concentration Profile Analysis

a

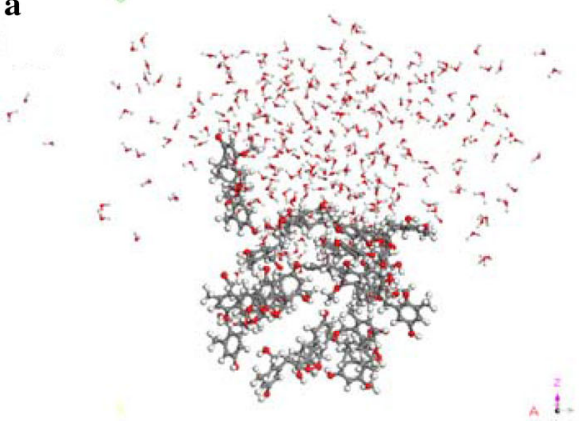

b

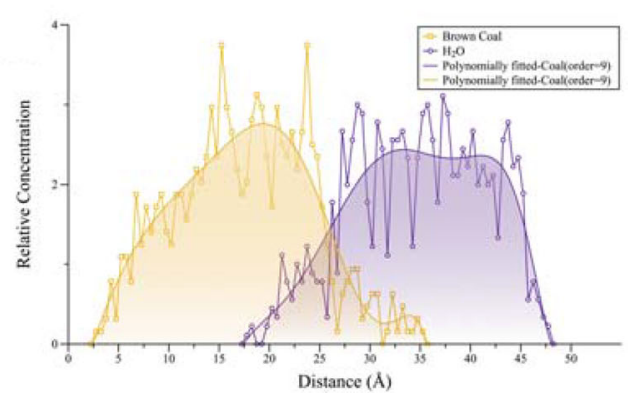

Fig. 9 Forcite MD simulation results of small-scale 2D periodic surface Coal- $\mathrm{H}_{2} \mathrm{O}$ Molecular System at 293 K and NVT. a Dynamics output configuration; b Relative concentration by concentration profile analysis
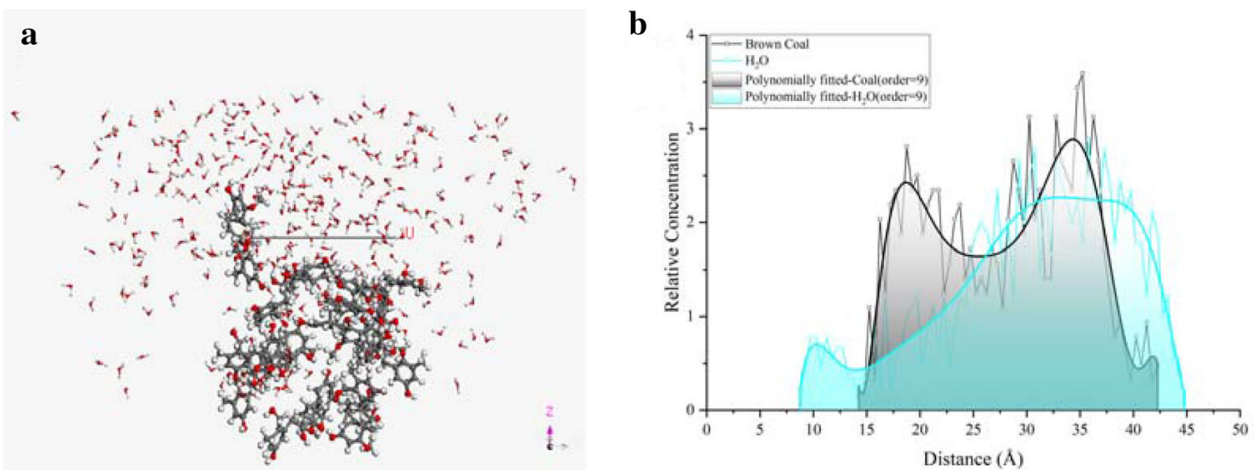

Fig. 10 MD simulation results of small-scale 2D periodic surface Coal- $\mathrm{H}_{2} \mathrm{O}$ molecular system (285 K, NVE). a Dynamics output configuration; b Relative concentration analysis 
a

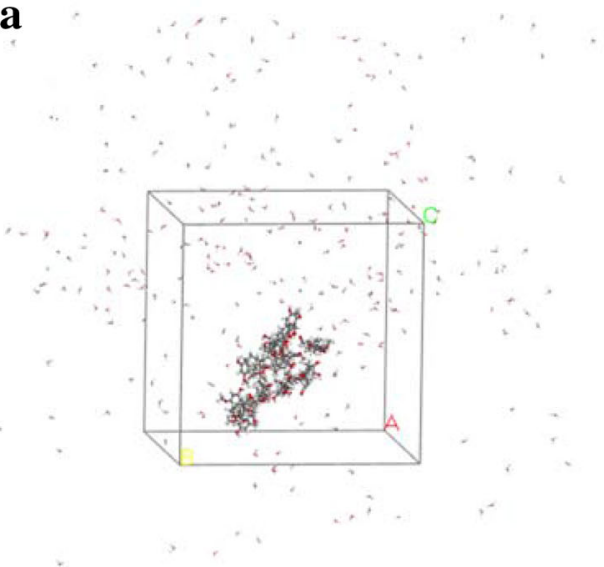

b

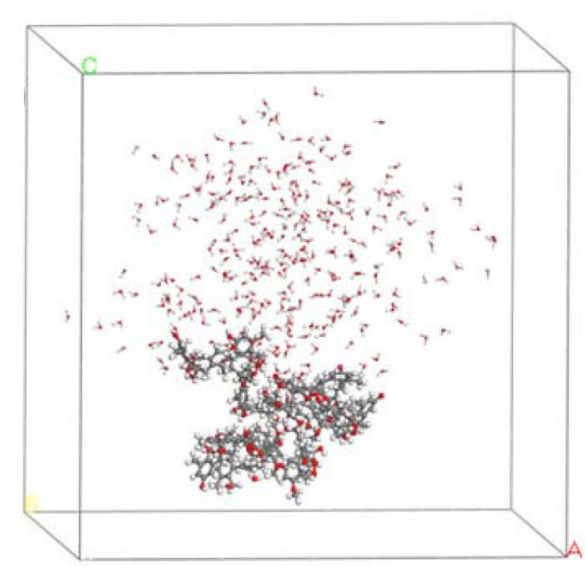

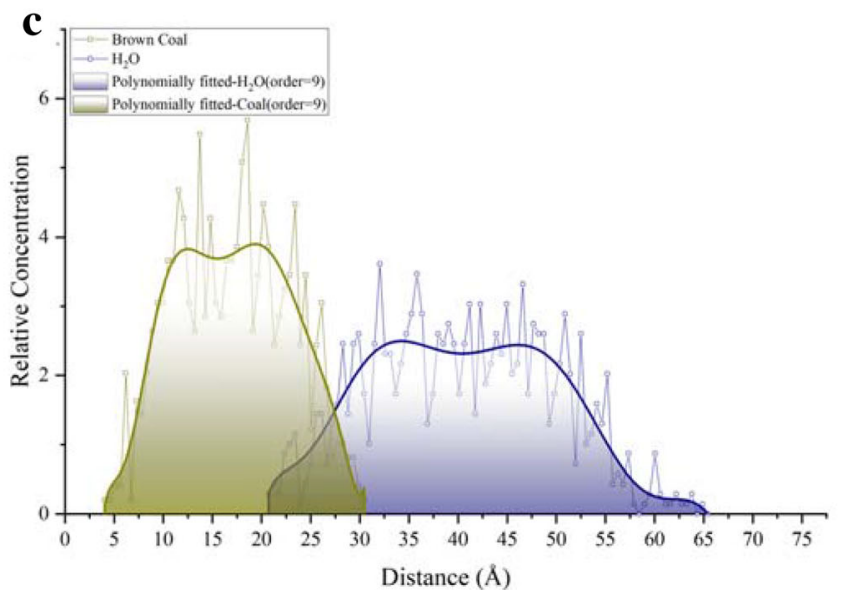

Fig. 11 Forcite MD simulation results of small-scale 3D periodic crystal Coal- $\mathrm{H}_{2} \mathrm{O}$ molecular system (285 K, NVT). a Without compressiondecompression treatment; $\mathbf{b}$ With compression-decompression treatment; $\mathbf{c}$ Relative concentration analysis (compression-decompression treated)

the periodic boundary conditions in $X, Y$ and $Z$ directions. After the establishment of the Coal dust- $\mathrm{H}_{2} \mathrm{O}$ Molecular System as a 3D periodic cell, a vacuum layer with a certain thickness was attached between the molecular layers of lignite and $\mathrm{H}_{2} \mathrm{O}$ by default. This was operated as "lignite molecular layer-vacuum layer- $\mathrm{H}_{2} \mathrm{O}$ molecular layervacuum layer" by Forcite in the $Z$ axis direction. This type of perpetually periodic structure is technically known as images of the lignite and $\mathrm{H}_{2} \mathrm{O}$ molecular layer above and below the simulation box and when $\mathrm{H}_{2} \mathrm{O}$ molecules run out of the box, there are corresponding images that run into the box to maintain the constant particle number. In order to study the interaction of the two layers of materials, the cutoff radius cannot be set too small, which can be a solution in other circumstances. Consequently, this influence cannot be avoided under 3D periodic boundary conditions. It does not have a significant influence on the $X O Y$ plane in this study; on the contrary, it can reflect the properties of a huge macro system into the established small simulation box, which greatly saves in terms of computing resources. However, it can interfere with the interaction of $\mathrm{H}_{2} \mathrm{O}$ molecules and coal dust in the $Z$ axis direction. The surface model with $2 \mathrm{D}$ periodic boundary has no periodicity in the $Z$ axis direction and the practice of this paper has verified that the interference of mirror image is avoided as a result, of which the comparison of Fig. 8a and Fig. 11a is an example.

In this paper, small systems are simulated prior to try various simulation conditions and gradually explore the superior simulation conditions such as ensemble, thermodynamic parameters, modeling methods which are suitable for the studied substance, systems and processes. The results show that $2 \mathrm{D}$ periodic surface structure perform well and it is necessary to take sufficient NPT pretreatment into consideration if a 3D periodic crystal structure is adapted. Besides, temperature variation was proven to be irrelevant under the simulation conditions of this paper. Thus, the most reliable results of medium and large systems can be obtained in the shortest time based on the research of small-scale coal- $\mathrm{H}_{2} \mathrm{O}$ molecular system under various conditions. 


\subsection{Medium-scale coal dust- $\mathrm{H}_{2} \mathrm{O}$ molecular system}

The medium-scale Coal dust $-\mathrm{H}_{2} \mathrm{O}$ Molecular System in this paper is consisted of $200 \mathrm{H}_{2} \mathrm{O}$ molecules and 20 lignite molecules. Firstly, the model was established according to the aforementioned modeling method and the fixed constraints of coal molecules were removed to carry out a full geometric optimization. Then, the NVE annealing, which was different from the previous NVT annealing, was carried out along with geometric optimization as shown in Fig. 12a. Finally, the first NVT dynamic simulation with the same parameters was carried out. Before the second NVT simulation, the original NVT annealing and fixing constraints of the coal layer were applied as before, with the same kinetic parameters as shown in Fig. 13a.

Figure $12 \mathrm{~b}, \mathrm{c}$ show the output structure image and relative concentration analysis after the simulations respectively. It is evident that the coal molecular layer displacement in the first simulation was extremely large. Due to the unconstrained Cartesian coordinates and fractional coordinates, the coal molecules were fully aggregated, forming a structure closer to the actual coal molecular state. Yet the simulation result image shows that the $\mathrm{H}_{2} \mathrm{O}$ molecular diffusion was intense and did not show obvious contact characteristics with coal. It is speculated that the whole and local positions of the coal layer were constantly changing, making it difficult for $\mathrm{H}_{2} \mathrm{O}$ molecular layer to fully interact with it. In addition, the annealing was carried out under NVE, an isolated system and the intense diffusion of $\mathrm{H}_{2} \mathrm{O}$ molecules in consistency with the results of previous section, also affected the dynamic simulation that followed. As a result, NVT annealing and fixed coal molecular layer simulation are suitable to the focus of this research. The second simulation result, adopting the above methods, showed that with the expansion of the simulation system, the $\mathrm{H}_{2} \mathrm{O}$ molecules' penetration into the coal dust and the outward diffusion effect of $\mathrm{H}_{2} \mathrm{O}$ molecules throughout the system were both weakened. At the end of the simulation, as shown in Fig. 13b, the $\mathrm{H}_{2} \mathrm{O}$ molecular layer was more concentrated on the coal layer surface of

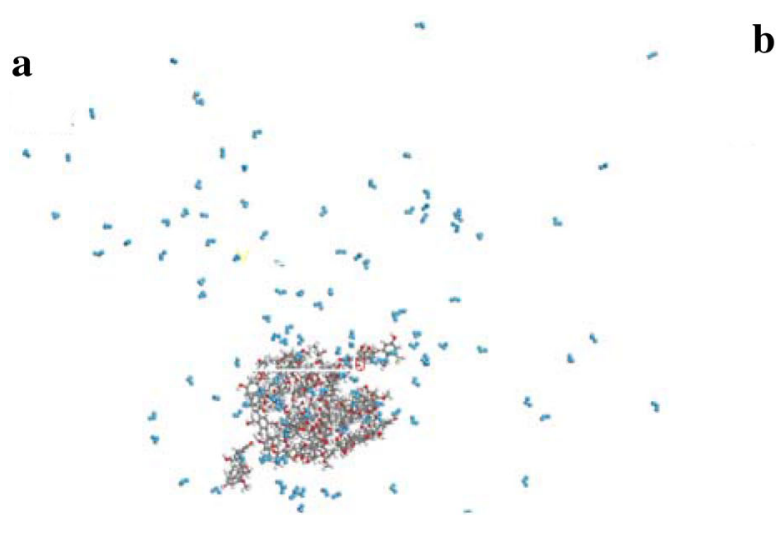

b

c

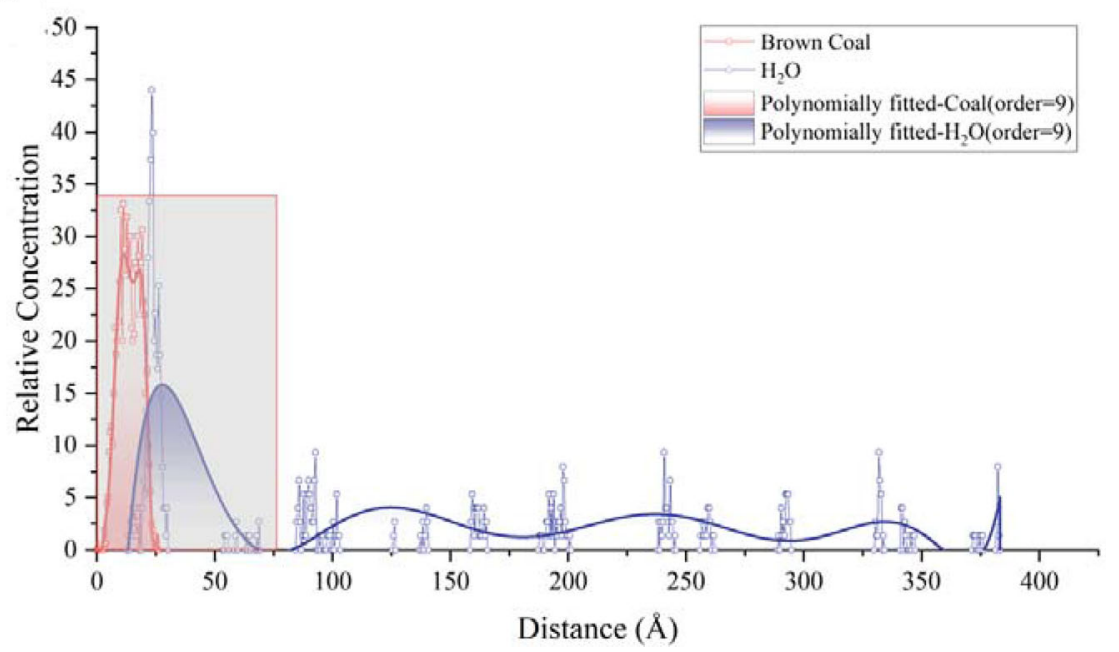

Fig. 12 MD simulation results of medium-scale 2D periodic surface Coal- $\mathrm{H}_{2} \mathrm{O}$ molecular system (285 K, NVT dynamics, annealed in NVE, coal layer unfixed). a After NVE anneal; b Dynamics output configuration; c Relative concentration analysis 

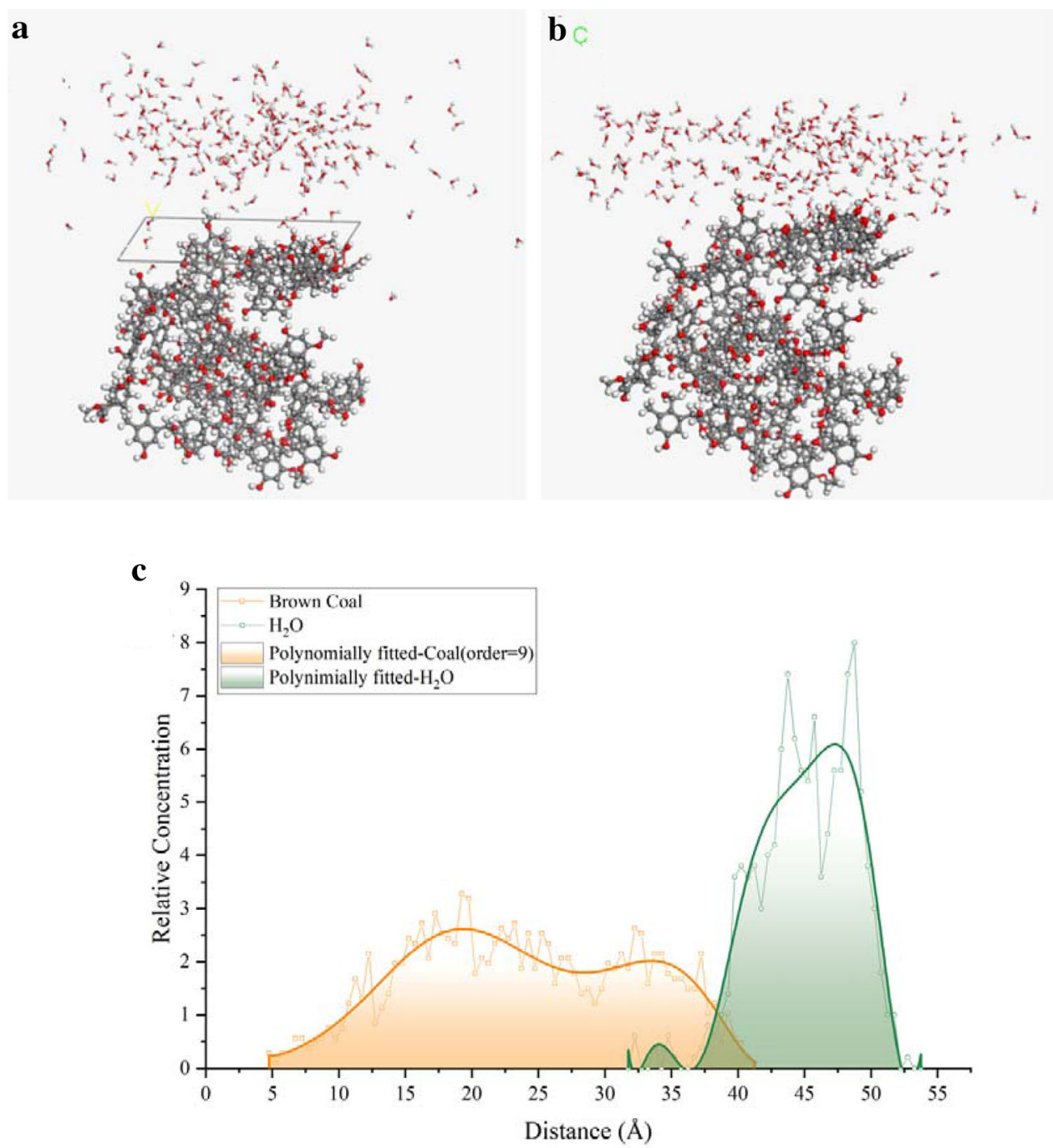

Fig. 13 MD simulation results of medium-scale 2D periodic surface Coal- $\mathrm{H}_{2} \mathrm{O}$ Molecular System (285 K, NVT dynamics, annealed in NVT, coal layer fixed). a After NVT anneal; b Dynamics output configuration; c Relative concentration analysis

the larger system. One possible reason for this is the stronger attraction of the larger coal dust system to $\mathrm{H}_{2} \mathrm{O}$ molecules. This result may better reflect the contact characteristics of $\mathrm{H}_{2} \mathrm{O}$ molecules as a whole with coal dust. The concentration analysis (Fig. 13c) shows that the coal molecular layer was distributed in the range of $4.8-41.3 \AA$ from the bottom to the top of the crystal cell, while the $\mathrm{H}_{2} \mathrm{O}$ molecule was distributed in the range of 31.9-53.2 $\AA$. The furthest $\mathrm{H}_{2} \mathrm{O}$ molecule only penetrated to approximately $9 \AA$ into the coal dust, accounting for $24.66 \%$ of the distribution range of the $Z$ axis of the coal molecular layer, with a low relative concentration value. However, the $\mathrm{H}_{2} \mathrm{O}$ molecules were concentrated in a small range of coal dust surface with a high relative concentration value, accounting for $32.60 \%$ of the $Z$ axis distribution range of the coal molecular layer, demonstrating clear characteristics of the wetting process and concentration mutation which is a sign of a boundary.

\subsection{Large-scale coal dust- $\mathrm{H}_{2} \mathrm{O}$ molecular system}

The large-scale Coal dust- $\mathrm{H}_{2} \mathrm{O}$ Molecular System in this paper is consisted of a micro droplet system composed of $500 \mathrm{H}_{2} \mathrm{O}$ molecules and a coal dust system composed of 50 lignite molecules and is built as a $2 \mathrm{D}$ periodic surface model by the Build Layers command. Due to its large size, the lignite molecular layer was annealed and geometrically optimized with higher precision than the previously small and medium-sized systems before simulation. The temperature range was enlarged to $300-1000 \mathrm{~K}$ and the number of cycles was increased to 50 . The output configuration is shown in Fig. 14a. 


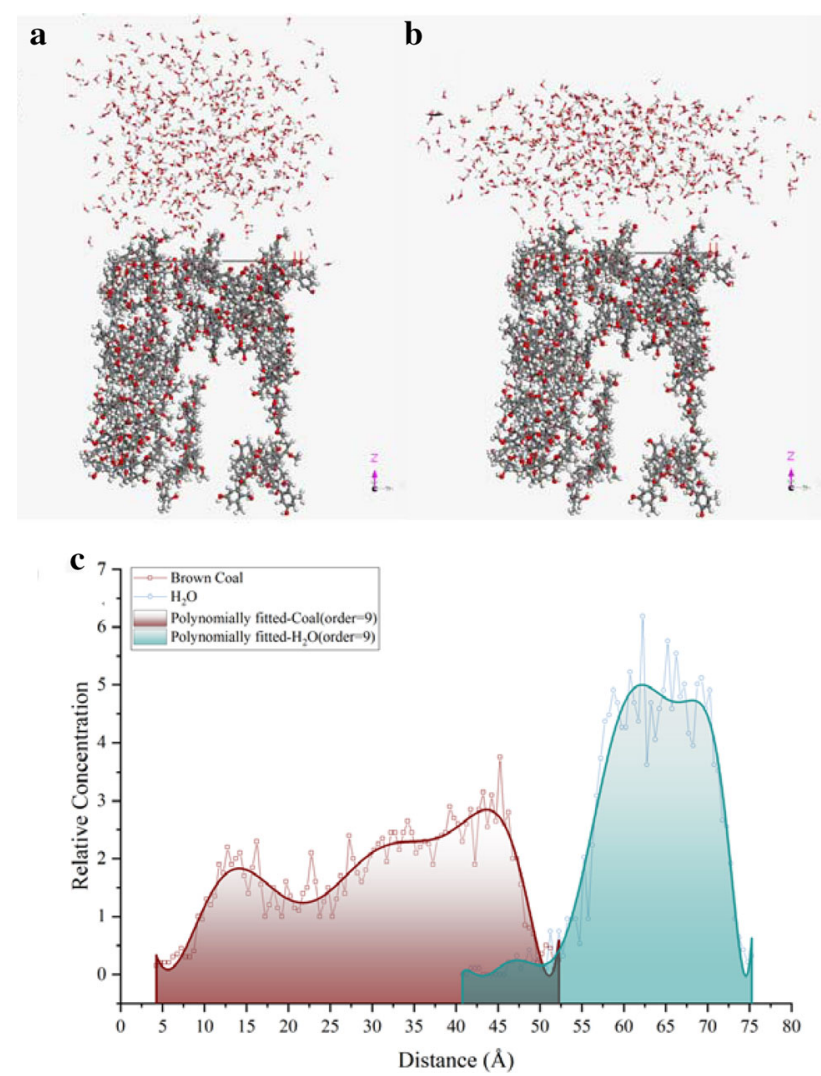

Fig. $14 \mathrm{MD}$ simulation results of large-scale 2D periodic surface Coal- $\mathrm{H}_{2} \mathrm{O}$ Molecular System. a After NVT anneal; b Dynamics output configuration; c Relative concentration analysis

The configuration and relative concentration analysis were obtained as shown in Fig.14b, c after dynamic simulation. Instead of wide-scale diffusion of the $\mathrm{H}_{2} \mathrm{O}$ layer, its stable displacement towards the coal molecular layer was obvious as expected. Thus, under this condition, the
$\mathrm{H}_{2} \mathrm{O}$ molecules had sharper aggregation and horizontal extension tendencies on the surface of the coal dust.

All of the Molecular Dynamic simulations in this paper have been completed. Typical relative concentration analysis results were compiled and sorted as shown Table 2 . The differences in simulation results under different conditions are clearly presented.

\section{Conclusion}

Employing molecular dynamics simulations under various conditions for investigation, this paper establishes suitable model and determines dynamics simulation method in the wetting process. the results were compiled as followed:

(1) The simulated results obtained by annealing and calculation under NVT ensemble are superior to those obtained by NVE ensemble. The diffusion and infiltration of $\mathrm{H}_{2} \mathrm{O}$ molecules in the NVT ensemble are weaker than that in the NVE ensemble, so it is more suitable for simulating the process of coal dust wetting.

(2) In modeling, the $2 \mathrm{D}$ periodic surface structure is more reasonable than the 3D periodic crystal structure. This model avoids the periodic mirror-image interference in the $Z$ axis direction of the study and the results can better reflect the research focus of wettability. After the simulation, 3D particle distribution can also be done to analyze quantitatively.

(3) The wetting behavior of $\mathrm{H}_{2} \mathrm{O}$ molecules can be better reflected in a large scale system of coal dust and $\mathrm{H}_{2} \mathrm{O}$ molecules. The results of relative concentration analysis showed that the relative concentration range of $\mathrm{H}_{2} \mathrm{O}$ molecules in the optimal

Table 2 Relative concentration results

\begin{tabular}{|c|c|c|c|c|c|c|c|}
\hline $\begin{array}{l}\text { System } \\
\text { scale }\end{array}$ & $\begin{array}{l}\text { Temperature } \\
(\mathrm{K})\end{array}$ & $\begin{array}{l}\text { Anneal } \\
\text { ensemble }\end{array}$ & $\begin{array}{l}\text { Dynamic } \\
\text { ensemble }\end{array}$ & $\begin{array}{l}\text { Boundary/Model } \\
\text { type }\end{array}$ & $\begin{array}{l}\text { Press } \\
(\mathrm{MPa})\end{array}$ & $\begin{array}{l}\text { Relative } \mathrm{H}_{2} \mathrm{O} \text { concentrate } \\
\text { range }(\%, \AA / \AA)\end{array}$ & $\begin{array}{l}\text { Relative concentration } \\
\text { (fluctuation range) }\end{array}$ \\
\hline \multirow[t]{4}{*}{ Small } & 285 & NVT & NVE & $\begin{array}{l}\text { 2D } \\
\text { periodic/surface }\end{array}$ & - & Intensivelydiffuses & - \\
\hline & & & NVT & $\begin{array}{l}\text { 3D periodic/ } \\
\text { lattice }\end{array}$ & - & $\begin{array}{l}\text { Intensively diffuses and } \\
\text { permeates }\end{array}$ & - \\
\hline & & & NVT & $\begin{array}{l}\text { 3D periodic/ } \\
\text { lattice }\end{array}$ & $1-0.1$ & $90.741 \%$ & $2-3$ \\
\hline & & & NVT & $\begin{array}{l}\text { 2D } \\
\text { periodic/surface }\end{array}$ & - & $56.25 \%$ & $2-3$ \\
\hline \multirow[t]{2}{*}{ Medium } & 285 & $\begin{array}{l}\text { NVT(coal } \\
\text { unfixed) }\end{array}$ & NVT & $\begin{array}{l}\text { 2D } \\
\text { periodic/surface }\end{array}$ & - & Intensively diffused & - \\
\hline & & NVT & NVT & $\begin{array}{l}\text { 2D } \\
\text { periodic/surface }\end{array}$ & - & $32.60 \%$ & $5-8$ \\
\hline Large & 285 & NVT & NVT & $\begin{array}{l}\text { 2D } \\
\text { periodic/surface }\end{array}$ & - & $25 \%$ & $4-6$ \\
\hline
\end{tabular}


simulation results for each system scale decreased with the increase of the system scale, which are $56.25 \%, 32.60 \%$ and $25 \%$, respectively, indicating that $\mathrm{H}_{2} \mathrm{O}$ molecules tended to adhere to the surface of coal dust in the large system.

Acknowledgements This work was supported by the National Natural Science Foundation of China (51874290), Jiangsu Province "Qinglan Project" and the Fundamental Research Funds for the Central Universities (2019XKQYMS74).

\section{Compliance with ethical sandards}

Conflict of interest We claim that none of the material in the paper has been published or is under consideration for publication elsewhere and there is no conflict of interest with others.

Open Access This article is licensed under a Creative Commons Attribution 4.0 International License, which permits use, sharing, adaptation, distribution and reproduction in any medium or format, as long as you give appropriate credit to the original author(s) and the source, provide a link to the Creative Commons licence, and indicate if changes were made. The images or other third party material in this article are included in the article's Creative Commons licence, unless indicated otherwise in a credit line to the material. If material is not included in the article's Creative Commons licence and your intended use is not permitted by statutory regulation or exceeds the permitted use, you will need to obtain permission directly from the copyright holder. To view a copy of this licence, visit http://creativecommons. org/licenses/by/4.0/.

\section{References}

Abdulnour Y, Toukmaji JAB (1996) Ewald summation techniques in perspective: a survey. Comput Phys Commun 95:73-92

Cheng WM, Nie W, Zhou G, Yu Y, Ma Y, Xue J (2012) Research and practice on fluctuation water injection technology at low permeability coal seam. Saf Sci 50:851-856. https://doi.org/10. 1016/j.ssci.2011.08.021

Glukhova OE (2017) Chapter 10-molecular dynamics as the tool for investigation of carbon nanostructures properties. Thermal Transp Carbon-Based Nanomater 5:267-289

Imai Y, Mukaida M, Tsunoda T (2001) Calculation of electronic energy and density of state of iron-disilicides using a totalenergy pseudopotential method. CASTEP Thin Solid Films 381:176-182

Liu Z, Zhou G, Li S, Wang C, Liu R, Jiang W (2020) Molecular dynamics simulation and experimental characterization of anionic surfactant: Influence on wettability of low-rank coal. Fuel 279:118323. https://doi.org/10.1016/j.fuel.2020.118323

Luo Y, Wang DM, Cheng JW (2017) Effects of rock dusting in preventing and reducing intensity of coal mine explosions. Int $\mathrm{J}$ Coal Sci Technol 4(2):102-109
Meng J, Yin F, Li S, Zhong R, Sheng Z, Nie B (2019) Effect of different concentrations of surfactant on the wettability of coal by molecular dynamics simulation. Int $\mathrm{J}$ Min Sci Technol 29:577-584. https://doi.org/10.1016/j.ijmst.2019.06.010

Reed WR, Zheng Y, Yekich M, Ross G, Salem A (2018) Laboratory testing of a shuttle car canopy air curtain for respirable coal mine dust control. Int J Coal Sci Technol 5(3):305-314

Reed WR, Shahan M, Klima S, Ross G, Singh K, Cross R, Grounds T (2019) Field study results of a 3rd generation roof bolter canopy air curtain for respirable coal mine dust control. Int J Coal Sci Technol 7:79-87. https://doi.org/10.1007/s40789-019-00280-5

Savin AV, Mazo MA (2020) The COMPASS force field: Validation for carbon nanoribbons Physica E: low-dimensional. Syst Nanostruct 118:113937. https://doi.org/10.1016/j.physe.2019. 113937

Shahan Michael R, Randolph RW (2019) The design of a laboratory apparatus to simulate the dust generated by longwall shield advances. Int J Coal Sci Technol 6(4):577-585

Sharma S (2019) Applications of BIOVIA Materials Studio, LAMMPS and GROMACS in Various Fields of Science and Engineering. Molecular Dynamics Simulation of Nanocomposites Using BIOVIA Materials Studio, Lammps and Gromacs. https://doi.org/10.1016/B978-0-12-816954-4.00007-3

Tan B, Liu HL, Xu B, Wang T (2020) Comparative study of the explosion pressure characteristics of micro-and nano-sized coal dust and methane-coal dust mixtures in a pipe. Int $\mathbf{J}$ Coal Sci Technol 7(1):68-78

Wang H, Wang D, Tang Y, Qin B, Xin H (2014) Experimental investigation of the performance of a novel foam generator for dust suppression in underground coal mines. Adv Powder Technol 25:1053-1059. https://doi.org/10.1016/j.apt.2014.02. 011

Wang H, Wang C, Wang D (2017) The influence of forced ventilation airflow on water spray for dust suppression on heading face in underground coal mine. Powder Technol 320:498-510. https:// doi.org/10.1016/j.powtec.2017.07.069

Wang P, Tan X, Zhang L, Li Y, Liu R (2019) Influence of particle diameter on the wettability of coal dust and the dust suppression efficiency via spraying. Process Saf Environ Prot 132:189-199. https://doi.org/10.1016/j.psep.2019.09.031

Xia Y (2017) Molecular simulations on adsorption of water onto lignite surface and its wettability modification. Dissertation, Taiyuan University of Technology

Xu S, Wang G, Liu HM, Wang LJ, Wang HF (2007) A DMol 3 study on the reaction between trans-resveratrol and hydroperoxyl radical: Dissimilarity of antioxidant activity among O-H groups of trans-resveratrol. J Mol Struct (Thoechem) 809:79-85

$\mathrm{Xu} \mathrm{C}$ et al (2017) Effects of chemical properties of coal dust on its wettability. Powder Technol 318:33-39. https://doi.org/10.1016/ j.powtec.2017.05.028

Yan ZC, Luo YS (2014) A particle swarm optimization algorithm based on simulated annealing. In: Advanced materials research. Trans Tech Publ 23: 2301-2305

Yao HF, Wang HY, Li YC, Jin L (2020) Three-dimensional spatial and temporal distributions of dust in roadway tunneling. Int $\mathrm{J}$ Coal Sci Technol 7:88-96. https://doi.org/10.1007/s40789-02000302-7 